\title{
Physical and environmental properties of asphalt mixtures containing incinerator bottom ash
}

\author{
Chin-Ming Huang ${ }^{\text {a }}$, Chui-Te Chiu ${ }^{\text {b,* }}$, Kung-Cheh Li ${ }^{a}$, Wan-Fa Yang ${ }^{b}$ \\ ${ }^{a}$ Graduate Institute of Environmental Engineering, National Taiwan University, Taiwan \\ ${ }^{\mathrm{b}}$ Chung Hua University, Department of Civil Engineering, No. 707 Sec. 2, WuFu Rd., Hsin Chu 300, Taiwan
}

Received 21 February 2006; received in revised form 3 May 2006; accepted 5 May 2006

Available online 12 May 2006

\begin{abstract}
This paper presents parts of the results from a research project sponsored by Taiwan Environmental Protection Administration (TEPA), investigating both the physical and environmental properties of asphalt mixtures using different amount of incinerator bottom ash (IBA) as fine aggregate substitution. The Marshall mix design method was used to determine the design asphalt content and evaluate the potential performance of these IBA-asphalt mixtures. Water sensitivity and wheel track rutting were also performed on these mixtures. Leachates, from both laboratory and outdoor leaching tests, were performed to measure the concentration of selected heavy metals and the level of daphnia toxicity. While with adequate Marshall stability, the IBA-asphalt mixtures were shown to have excessively high Marshall flow and excessively low VMA (voids in the mineral aggregate). The results of the wheel tracking tests also indicated that the IBA-asphalt mixtures had low rutting resistance. The results of the water sensitivity test according to procedure of AASHTO T283 method showed that the IBA-asphalt mixtures had a higher tensile strength ratio (TSR) as compared with the conventional asphalt mixtures. Considering the environmental aspects, outdoor leaching tests showed that IBA had a high level of daphnia toxicity. From an ecological perspective, IBA could be identified as hazardous waste in Taiwan. However, after being mixed with asphalt binder, the concentration of heavy metals and the levels of daphnia toxicity were significantly reduced. The leachates of 10-day flat plate leaching tests on Marshall specimens containing IBA indicated that the heavy metal were undetectable and the daphnia toxicity was ineffective. (C) 2006 Published by Elsevier B.V.
\end{abstract}

Keywords: Incinerator bottom ash; Asphalt mixture; Leachate; Heavy metal; Daphnia toxicity

\section{Introduction}

In 2004, Taiwan Environmental Protection Administration (TEPA) promoted the "THREE-YEAR ENVIRONMENTAL ACTION PLAN: complete sorting and recycling to meet ultimate goal of zero waste." Besides establishing and promoting the material recycling facility programs, TEPA proceeds the beneficial utilization of incinerator bottom ash (IBA) in order to achieve the ultimate goal of zero-bury. IBA can approach the properties of sand and gravel with proper treatment. In general, 800,000 metric tonnes of IBA, produced yearly by the 20 wasteto-energy (WTE) facilities in Taiwan, are introduced to be used as aggregate substituted materials in construction applications.

\footnotetext{
* Corresponding author. Tel.: +886 3 5186715; fax: +88635372188.

E-mail addresses: d90541011@ntu.edu.tw (C.-M. Huang), ctc@chu.edu.tw (C.-T. Chiu), kcli@ntu.edu.tw (K.-C. Li), Wfyang@ccms.ntu.edu.tw (W.-F. Yang).
}

The IBA from WTE facilities appears like a porous, grayish, silty sand and gravel, and contains small amounts of unburned organic material and chunks of metal. Previous TEPA funded studies had analyzed and listed the major, minor, and trace elements of IBA sampling from the conventional ash handling process. As shown in Table 1, the major components are silica $\left(\mathrm{SiO}_{2}\right)$, alumina $\left(\mathrm{Al}_{2} \mathrm{O}_{3}\right)$, ferric oxide $\left(\mathrm{Fe}_{2} \mathrm{O}_{3}\right)$, and lime $(\mathrm{CaO})$, accompanied by soluble magnesia and alkalis $\left(\mathrm{K}_{2} \mathrm{O}\right.$ and $\left.\mathrm{Na}_{2} \mathrm{O}\right)$. Using IBA as substituted materials, the potential hydration and expansion of soluble salts are possible causes for volume stability problems in secondary building material. In recent years, the presence of high content of salt and concentrations of trace metal in IBA including lead, cadmium, and zinc has raised concerns with the environmental acceptability of using IBA as aggregate substituted material [1].

According to the experience of European countries, the processing of IBA requires at least 30 days storage for potentially hydration and expansion by reaction with soluble salts before 
Table 1

Typical chemical components of IBA [1]

\begin{tabular}{|c|c|c|c|c|c|}
\hline Major component & Range (\%) & Minor component & Range (\%) & Trace component & Range $(\mathrm{mg} / \mathrm{kg})$ \\
\hline $\mathrm{SiO}_{2}$ & $37.68-43.30$ & $\mathrm{CuO}$ & $0.26-0.40$ & $\mathrm{BaO}$ & $687-1090$ \\
\hline $\mathrm{Al}_{2} \mathrm{O}_{3}$ & $5.99-6.08$ & $\mathrm{ZnO}$ & $0.38-0.57$ & Total Cr & 258-208 \\
\hline $\mathrm{Fe}_{2} \mathrm{O}_{3}$ & $7.92-9.49$ & $\mathrm{MnO}_{2}$ & $0.14-0.19$ & $\mathrm{SrO}$ & $264-378$ \\
\hline $\mathrm{CaO}$ & $13.03-16.72$ & $\mathrm{TiO}_{2}$ & $0.41-0.47$ & $\mathrm{Bi}_{2} \mathrm{O}_{3}$ & $190-334$ \\
\hline $\mathrm{MgO}$ & $1.35-1.39$ & $\mathrm{~S}$ & $0.48-0.52$ & $\mathrm{Co}_{3} \mathrm{O}_{4}$ & $46-64$ \\
\hline $\mathrm{Na}_{2} \mathrm{O}$ & $1.04-3.22$ & & & $\mathrm{NiO}$ & $246-318$ \\
\hline $\mathrm{P}_{2} \mathrm{O}_{5}$ & $1.87-3.01$ & & & $\mathrm{Sb}_{2} \mathrm{O}_{3}$ & $180-247$ \\
\hline $\mathrm{K}_{2} \mathrm{O}$ & $1.02-1.06$ & & & $\mathrm{SnO}_{2}$ & $381-449$ \\
\hline \multirow[t]{4}{*}{$\mathrm{Cl}$} & $0.81-1.15$ & & & $\mathrm{~V}_{2} \mathrm{O}_{3}$ & $59-76$ \\
\hline & & & & $\mathrm{PbO}$ & $608-2500$ \\
\hline & & & & $\mathrm{CdO}$ & $\sim 29$ \\
\hline & & & & $\mathrm{Hg}$ & 0.35 \\
\hline
\end{tabular}

Note: Loss on ignition are $6.39-11.21 \%$ at $1000{ }^{\circ} \mathrm{C}$.

using the material in construction application. The patented process asks for chemical fixation agents to permanently immobilize concerned heavy metals palletizing them into graded aggregates [2]. TEPA asked all the WTE facilities to separate and carefully manage the bottom ash and fly ash stream with proper treatment.

Fig. 1 shows the flowchart of IBA innovative process, including sieve screener, magnetic separation, eddy current separation, air blower, and crusher, is approach to remove ferrous and nonferrous metals and unburned materials, and achieve an appropriate particle size gradation.

Related research on IBA as aggregate substituted materials has been performed in the United States for more than 20 years [1]. According to reports on its trial usage, most pavements using IBA had satisfactory performance, excluding one case with stripping problem was reported [1]. Furthermore, IBA with a higher loss on ignition, more than $10 \%$, can vary in asphalt absorptions during the IBA-asphalt mixing process, thus producing non-uniform mixtures [3,4]. With non-uniform asphalt absorption and an increase of asphalt content, the IBA utilized process becomes uneconomical. Although $50 \%$ by weight of aggregate has been used in pavements design, it is recommended that the substitution ratio of IBA was limited under $25 \%$ in binder or base course, and $15 \%$ or less in surface mixes to ensure satisfactory paving material production and field performance [1].

A study on asphalt encapsulation efficiency of IBA confirmed that the release of metal salt could be adequately suppressed using the asphalt encapsulation of ash particles, and the standards of pavement design of the New Hampshire State Department of Transportation could be satisfied [5].

There has been an increasing concern over the harmful release of heavy metals that might lead to a secondary pollution. It is considerable debate between the leaching methods on the use IBA and contaminants release potential using scientific assessment. To evaluate the toxicity of IBA, we carry out simulated experiments, besides collecting long-term actual field data. The National Cooperative Highway Research Program (NCHRP) suggested the use of flat plate leaching test in the laboratory to simulate the potential of pollutant leaching out from the IBA-asphalt mixtures for environmental impact assessment [6].

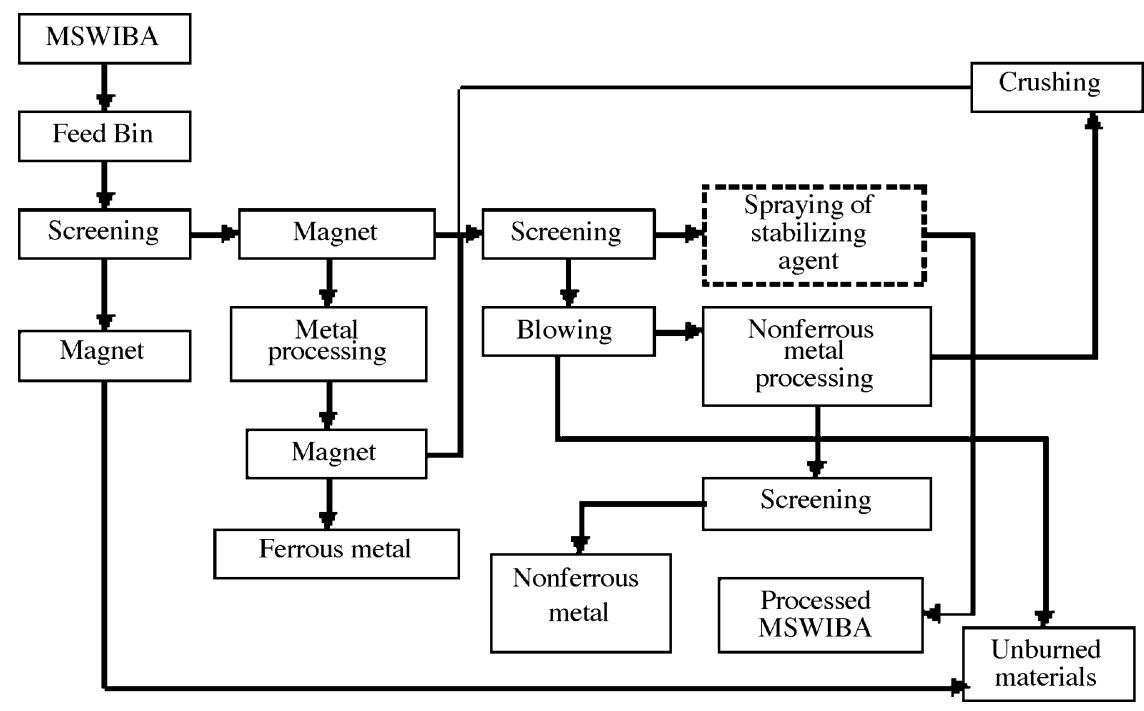

Fig. 1. Flowchart for processing IBA used in this study. 


\section{Materials and methods}

This research investigates the physical properties and environmental effects of asphalt mixtures containing varied ratio of IBA. First, the chemical properties of IBA were measured; then tests were run on the IBA-asphalt mixtures to evaluate their engineering performance as a paving material and finally, the leaching and environmental toxicity of the IBA-asphalt mixtures were measured.

\subsection{Chemical properties of IBA}

Representative samples of IBA were obtained from the ash treatment plant at northern Taiwan under a controlled process with no chemical fixation agents and washing occurrences. A comparable sample of washed IBA was also obtained for test. The chemical properties and methods performed on the treated IBA are listed in Table 2.

\subsection{Physical properties of IBA-asphalt mixtures}

In order to analyze the physical properties of asphalt mixtures containing IBA, the conventional Marshall mix design procedures were performed at different IBA substitution ratios. The asphalt content of pavement design was selected at $4 \%$ air voids for the 50-blow Marshall specimens. Then moisture damage and rutting resistance tests were carried out on the IBA-asphalt mixtures at the design asphalt content. The moisture damage test was performed using the procedures in AASHTO T283 method and the rutting resistance was performed following the procedures in Section 3-7-3 of the Japanese "Road Paving Test Regulation". The measures for physical properties of IBA-asphalt mixtures are shown in Fig. 2.

\subsection{Environmental impacts of IBA-asphalt mixtures}

The flowchart of the environmental impacts investigation of IBA-asphalt mixtures is shown in Fig. 3. There were four types of samples: IBA, asphalt mixture with $100 \%$ IBA $(9.5 \%$ asphalt binder), conventional asphalt mixture (0\% IBA), and Marshall

Table 2

Physical and chemical properties and methods performed on treated IBA

\begin{tabular}{ll}
\hline Property & Method code \\
\hline Gradation & ASTM $^{\mathrm{a}} \mathrm{C} 136$ \\
Specific gravity, absorption & ASTM C128 \\
pH Value & NIEA $^{\mathrm{b}}$ R208.03C \\
TCLP & NIEA R201.13C \\
Metal content of leachates (by flame atomic absorption spectrophotometer) \\
$\mathrm{Cd}$ & NIEA R302.20T \\
$\mathrm{Cr}$ & NIEA R303.20T \\
$\mathrm{Cu}$ & NIEA R305.20T \\
$\mathrm{Pb}$ & NIEA R306.20T \\
$\mathrm{Zn}$ & NIEA R307.20T \\
Daphnia toxicity of leachates & NIEA B901.11B
\end{tabular}

a ASTM: American Society for Testing and Materials.

b NIEA: National Institute of Environmental Analysis, EPA, Taiwan, R.O.C.

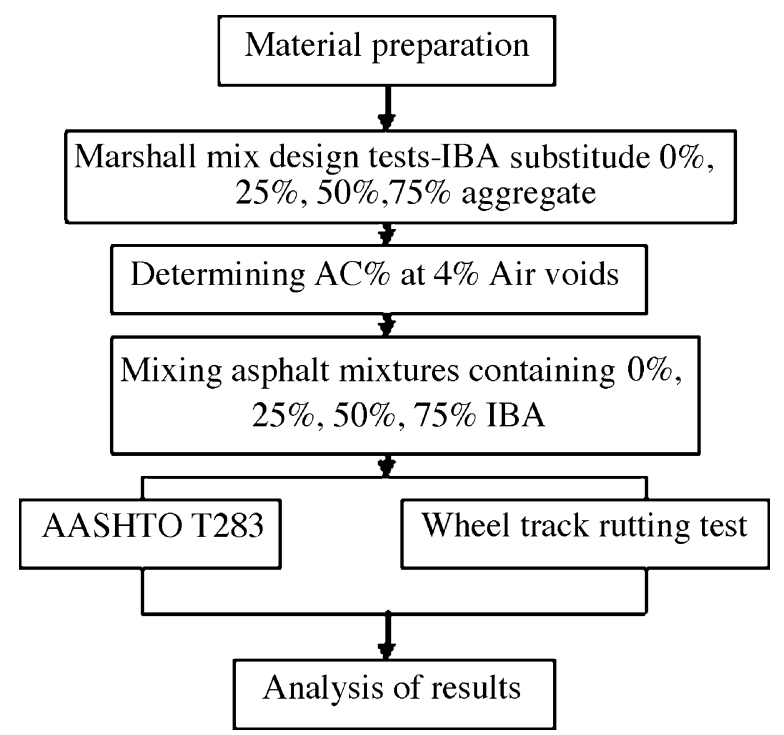

Fig. 2. Measures for physical properties of IBA-asphalt mixtures.

briquettes containing different percentage of IBA $(0,25,50$, and $75 \%$ ). By comparing asphalt mixtures with no substitution and $100 \%$ substitution, the effects of encapsulation of asphalt can be observed. These investigations were carried out in different leaching tests (i.e. TCLP, outdoor leaching, and flat plat leaching [6]) with IBA-asphalt mixtures. The leachates were collected for metal concentration and daphnia toxicity analysis. The heavy metals (cadmium, chromium, copper, lead, and zinc) were measured using the flame atomic absorption spectrophotometer (FAAS). The daphnia toxicity test was performed following NIEA B901.11B.

For environmental impact concern, the leachates were collected and diluted into five different concentrations (i.e. 100,

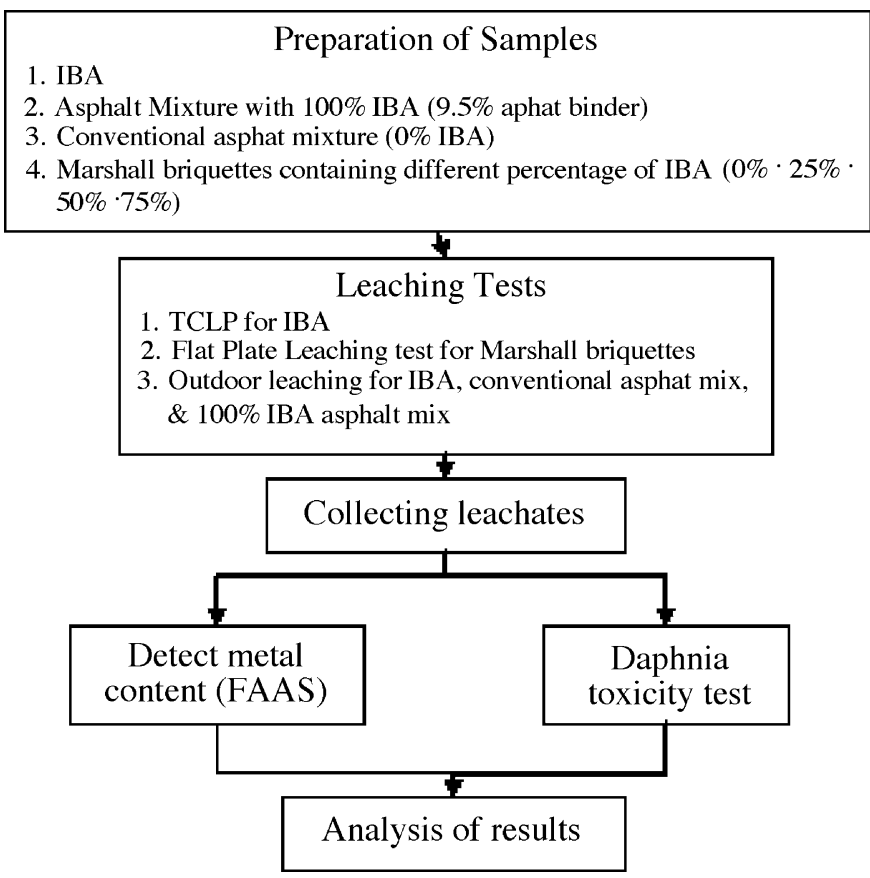

Fig. 3. Measures for environmental impacts of IBA-asphalt mixtures. 
$50,25,12.5$, and $6.25 \%$ ) for $24 \mathrm{~h}$ daphnia toxicity analysis. The $\mathrm{LC}_{50}$ represents the concentration of leachate that kill $50 \%$ of the daphnia relative to the surviving population in the control cultures. The value lower than $\mathrm{LC}_{50}$ implies greater toxicity. The toxicity levels is divided into five categories [6]: (A) no effect; (B) over $75 \%$ represents low toxicity; (C) 75 to $20 \%$ represents moderate toxicity; (D) 20 to $10 \%$ represents high toxicity; and (E) less than $10 \%$ means extremely high toxicity.

\section{Results and discussions}

The data obtained in this research are organized into three categories: chemical properties, physical properties, and environmental impact of IBA and IBA-asphalt mixtures. All data will be compared with the data from the washed IBA to make an overall assessment.

\subsection{Chemical properties of IBA}

Table 3 summarizes the physical and chemical properties of treated IBA used in this study. The gradation of treated IBA conforms to the gradation range specified in ASTM D1073 type IV, with a nominal maximum size of $9.5 \mathrm{~mm}$ (3/8 in.), $70 \%$ passing $4.76 \mathrm{~mm}$ (ASTM standard sieve no. 4), and $8 \%$ passing $0.074 \mathrm{~mm}$ (ASTM standard sieve no. 200). The oven dry specific gravity is around 1.85, and the absorption is $15 \%$ higher than the sand and the crushed stone. Glass particles and a small metal content are visible by looking at the retained particles on the $2.38 \mathrm{~mm}$ sieve. The $\mathrm{pH}$ value is determined to be 12 , which is highly alkaline. After washing, the oven dry specific gravity of the treated IBA raised to 2.28 , absorption reduced to $6 \%$, percent passing $0.074 \mathrm{~mm}$ reduced to $3 \%$, and the $\mathrm{pH}$ value changed to 10.

Table 4 indicates the heavy metal concentrations of leachates from TCLP of IBA. Compared with the present the TCLP limitations of the TEPA, heavy metals are below limitations. TCLP is ambiguous for assessing contaminants release in the European Union and the USA [7,8]. Obviously, the heavy metal
Table 4

Heavy metal concentrations of leachates from TCLP for IBA

\begin{tabular}{lllllc}
\hline Type & $\mathrm{Cd}$ & $\mathrm{Cr}$ & $\mathrm{Cu}$ & $\mathrm{Pb}$ & $\mathrm{Zn}$ \\
\hline Treated IBA & 0.18 & 0.24 & 4.88 & 0.66 & 55.8 \\
Washed IBA & 0.06 & 0.007 & 1.36 & 0.58 & 31.4 \\
TCLP limitation of TEPA & 1.0 & 5.0 & 15.0 & 5.0 & - \\
\hline
\end{tabular}

Unit: mg/L.

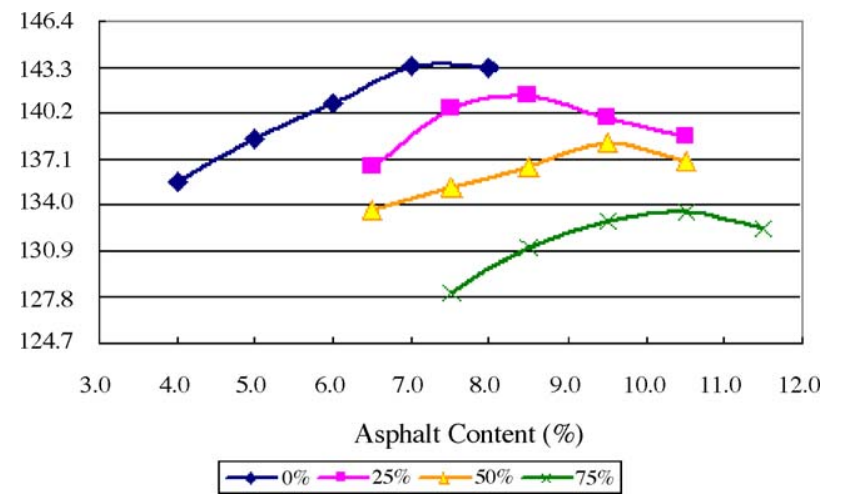

Fig. 4. Unit weight vs. asphalt content for IBA-asphalt mixtures.

concentrations of leachates after washing are lower than treated IBA. Therefore, the washing process not only removes fine particles, but also reduces the salty and metallic solids, produced wastewater required to proper treatment at IBA processing sites. Therefore, it is not recommended by the TEPA to adopt the water washing procedure in the process of treating IBA.

\subsection{Physical properties of IBA-asphalt mixtures}

As planned, the four mixtures with different IBA substitution rates were blended and mixed with a conventional asphalt binder at different contents to compact into Marshall specimens with 50 blows on each side. The unit weight, Marshall stability, and flow were measured. Fig. 4 shows the plot of unit weight versus asphalt content for the mixtures with different \% IBA substitu-

Table 3

Physical and chemical properties of IBA and conventional aggregates

\begin{tabular}{|c|c|c|c|c|c|c|}
\hline Item & Treated IBA & Washed IBA & Crushed stone 1 & Crushed stone 2 & Sand & ASTM D1073 type IV \\
\hline \multicolumn{7}{|l|}{ Gradation (\% passing) } \\
\hline $19 \mathrm{~mm}(3 / 4 \mathrm{in})$. & 100 & 100 & 100 & 100 & 100 & - \\
\hline $12.5 \mathrm{~mm}(1 / 2$ in. $)$ & 100 & 75.1 & 100 & 100 & 100 & - \\
\hline $9.5 \mathrm{~mm}(3 / 8 \mathrm{in})$. & 96.7 & 45.3 & 99.1 & 100 & 100 & 100 \\
\hline $4.76 \mathrm{~mm}$ (sieve no. 4 ) & 72.5 & 5.1 & 26.6 & 95.0 & 100 & $80-100$ \\
\hline $2.38 \mathrm{~mm}$ (sieve no. 8) & 51.8 & 2.4 & 4.6 & 74.7 & 71.4 & $65-100$ \\
\hline $1.19 \mathrm{~mm}$ (sieve no. 16$)$ & 34.9 & 2.0 & 2.6 & 58.5 & 47.8 & $40-80$ \\
\hline $0.59 \mathrm{~mm}$ (sieve no. 30 ) & 22.2 & 1.7 & 2.1 & 44.6 & 31.4 & $20-65$ \\
\hline $0.297 \mathrm{~mm}$ (sieve no. 50) & 14.8 & 1.5 & 1.8 & 29.0 & 18.7 & $7-40$ \\
\hline $0.149 \mathrm{~mm}$ (sieve no. 100$)$ & 9.7 & 1.2 & 1.4 & 12.0 & 8.6 & $2-20$ \\
\hline 0.074 mm (sieve no. 200) & 6.3 & 0.6 & 0.8 & 4.0 & 3.2 & $0-10$ \\
\hline Bulk specific gravity (oven dry) & 1.851 & 2.283 & 2.556 & 2.513 & 2.500 & - \\
\hline Absorption $(\%)$ & 15.7 & 6.0 & 2.0 & 2.6 & 2.4 & - \\
\hline Angularity (\%) & 41.4 & 54.4 & - & - & 46.0 & \\
\hline $\mathrm{pH}$ & 12.1 & 10.4 & - & - & 9.0 & - \\
\hline
\end{tabular}

Note: “_” not applicable. 


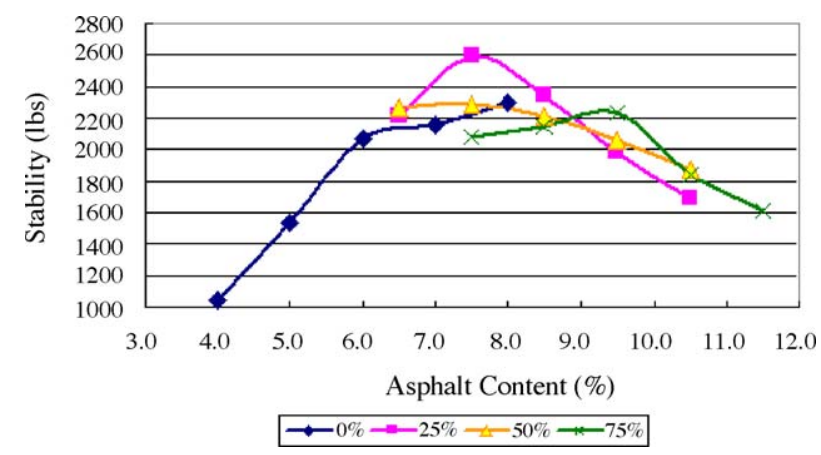

Fig. 5. Stability vs. asphalt content for IBA-asphalt mixtures.

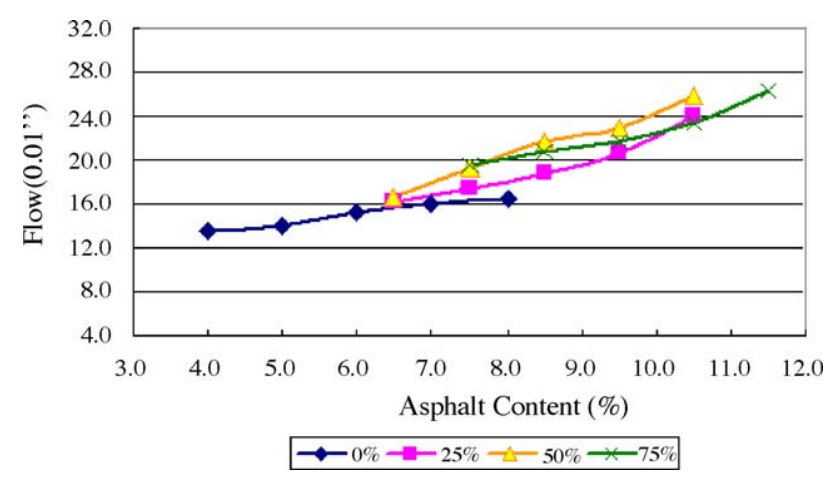

Fig. 6. Flow vs. asphalt content for IBA-asphalt mixtures.

tions. From the figure, one can see that all the curves representing unit weights, increase with the asphalt content, reaching the highest value, and then gradually decreases. The highest unit weight of each curve decreases with the increased amount of substitution rate, due to the lower IBA density, compared with the traditional aggregates. The asphalt content showing the highest unit weight increases with the increased amount of substitution, due to an increase of asphalt absorption.

The Marshall stability, flow, air voids, and VMA versus asphalt content of the asphalt mixtures containing 0-75\% IBA substitution are shown in Figs. 5-8, respectively. Fig. 5 shows that the Marshall stability of IBA-asphalt mixtures can satisfy the commonly used Marshall stability requirement, and is not necessarily lower than that of the traditional asphalt mixtures. Fig. 6 shows the Marshall flows of the IBA-asphalt mixtures exceed the common allowable limits, even at the low asphalt

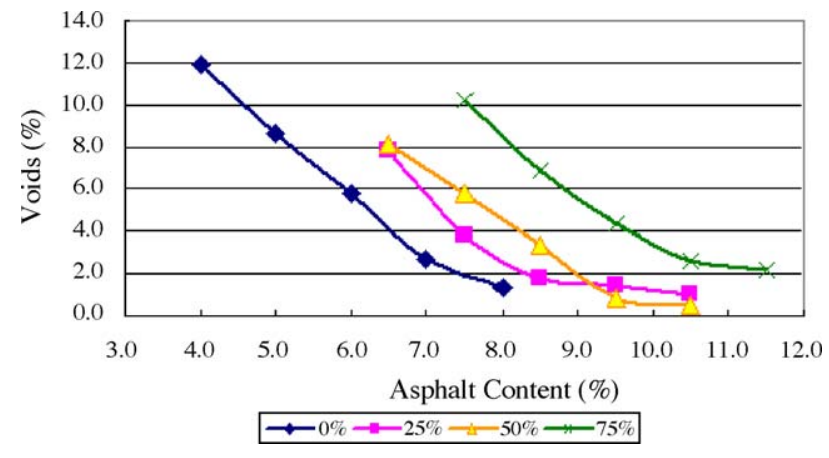

Fig. 7. Air void vs. asphalt content for IBA-asphalt mixtures.

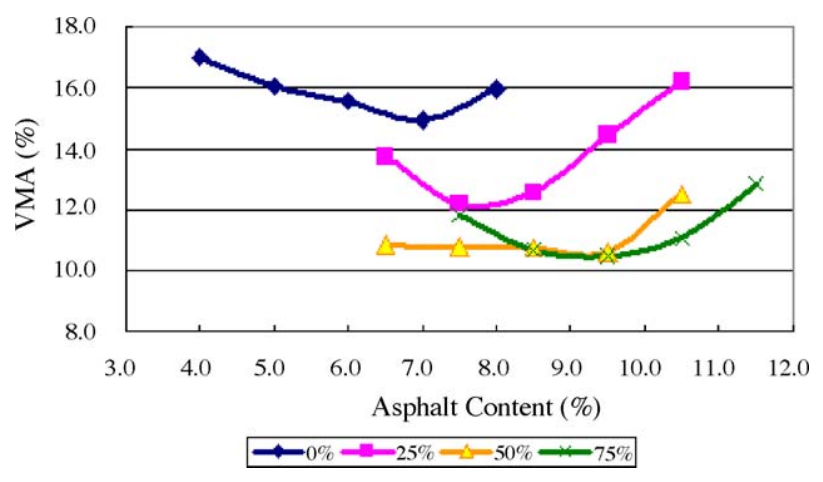

Fig. 8. VMA vs. asphalt content for IBA-asphalt mixtures.

content and do not show a clear trend with respect to the amount of IBA substitution. From Fig. 7, the two curves, representing 25 and $50 \%$ substitution, crossed at $9.0 \%$ asphalt content, above which the air voids are all below $2.0 \%$. In fact, the air voids are less than $1 \%$ for $50 \%$ substitution. Without enough void space between particles, the sample may have plastic flow phenomenon. Such phenomenon can also be seen in Fig. 8's VMA plots, which show low VMA values for the IBA-asphalt mixtures.

The experiment was carried out further to perform sieve analysis on solvent-extracted aggregates from the Marshall specimens. Table 5 summarizes the gradation data, before and after Marshall tests. There is a considerable increase of the fineness of the 50 and $75 \%$ substitution samples. This is because of the significant fracturing of the porous and fragile particles under compaction of the Marshall hammer. The fractured particles in the specimens caused the high Marshall flow and lower VMA.

Using the asphalt content at $4 \%$ air voids as suggested for proportioning, the asphalt content is found to be $6.5,7.4,8.3$, and $9.7 \%$ for IBA substitution rate of $0,25,50$ and $75 \%$ respectively, increasing linearly with the amount of substitution, which is about $1.0 \%$ increase for every $25 \%$ substitution.

Reduced compaction efforts (i.e. number of blows) were used to produce Marshall specimens with the air void content of $7 \% \pm 1 \%$ for moisture susceptibility test, following the AASHTO T283 method. The tensile strength ratio (TSR) was determined to be $57.2,62.7,70.1$, and $72.6 \%$ for specimens with $0,25,50$, and $75 \%$ IBA respectively. It is believed that the IBA

Table 5

Gradation change for mixtures containing IBA after 50-blow compaction of Marshall hammer

\begin{tabular}{lrrrr}
\hline Size of sieve & \multicolumn{3}{l}{ IBA content $(\%)$} & \\
\cline { 2 - 5 } & \multicolumn{1}{c}{0} & \multicolumn{1}{c}{25} & \multicolumn{1}{c}{50} & \multicolumn{1}{c}{75} \\
\hline $12.5 \mathrm{~mm}$ (1/2 in.) & -0.2 & -1.2 & -1.0 & -1.2 \\
$9.5 \mathrm{~mm}$ (3/8 in.) & 0.8 & -0.6 & 0.9 & 2.3 \\
$4.76 \mathrm{~mm}$ (sieve no. 4) & 2.0 & 3.8 & 6.5 & 6.0 \\
$2.38 \mathrm{~mm}$ (sieve no. 8) & 0.7 & 2.8 & 6.3 & 4.6 \\
$1.19 \mathrm{~mm}$ (sieve no. 16) & 1.6 & 1.4 & 7.7 & 7.7 \\
$0.59 \mathrm{~mm}$ (sieve no. 30) & 2.1 & 1.3 & 7.0 & 8.9 \\
$0.297 \mathrm{~mm}$ (sieve no. 50) & 2.0 & 1.4 & 5.6 & 7.5 \\
$0.149 \mathrm{~mm}$ (sieve no. 100) & 1.2 & 1.2 & 3.4 & 6.0 \\
$0.074 \mathrm{~mm}$ (sieve no. 200) & 0.6 & 0.8 & 1.8 & 3.7 \\
\hline
\end{tabular}


Table 6

Calculations of total metal content from outdoor leaching tests (unit: $\mathrm{mg} / \mathrm{kg}$ )

\begin{tabular}{llllll}
\hline Conditions & & $\mathrm{Cd}$ & $\mathrm{Cr}$ & $\mathrm{Cu}$ & $\mathrm{Pb}$ \\
\hline Accumulated release of outdoor leaching test & IBA & 0.2 & 3.69 & 31,972 & 1.74 \\
& 100\% IBA asphalt mix & 0.0 & 0.095 & 0.22 & 0.074 \\
& Conventional asphalt mix & 0.005 & 0.059 & 0.04 & 0.78 \\
Acid digestion $^{\mathrm{a}}$ & IBA & 93 & 1996 & 36,000 & 22,400 \\
\hline
\end{tabular}

a Acid digestion of leachate for metal analysis, NIEA R306.11C.

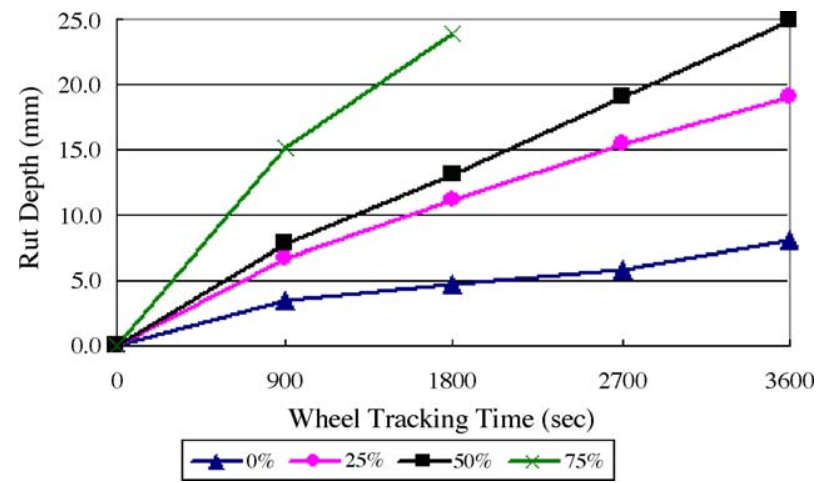

Fig. 9. Rut depth vs. wheel tracking time of IBA-asphalt mixtures.

ingredients of calcium oxide and other salts could be the possible reason for the increase of TSR. Field performance data are needed before making a conclusion on strengthening effect of IBA for moisture damage.

The Japanese's wheel tracking test method was performed to evaluate the effect of substitution. The rut depth versus wheel tracking times are plotted in Fig. 9, showing greater rut depth when IBA is added. The condition worsens as the amount of IBA increases. The experiment was forced to be stopped while testing the $75 \%$ IBA samples, because the rut depth had surpassed $20 \mathrm{~mm}$.

\subsection{Environmental impacts of IBA-asphalt mixtures}

Heavy metal concentration data from leachates of outdoor precipitation leaching tests are below the TCLP limitations, with most leachates even undetectable. Multiplied by the accumulated volume of precipitation during the 3 months, the total amount of metals leached out from the mixture specimens was calculated as shown in Table 6. Comparing with the acid digestion of IBA, which is the total or 'near total' content of heavy metal, although copper is the easiest to extract, after the asphalt encapsulation, the leachate of copper was reduced significantly. All the other kinds of metals in this investigation behaved the same way due to the asphalt encapsulation.

Table 7 shows the heavy metal concentrations of leachates from flat plate leaching test on the Marshall specimens with IBA substituted. Most of the data are below the detection limits, and no trend is found as to the effects of leaching time or IBA content on the concentration of the metal leachates. Nevertheless, comparing with the concentrations in Tables 4 and 6, the effect of compaction and the asphalt encapsulation on the metal leachates are identified.

Table 8 presents the results of daphnia toxicity tests for leachates collected from the outdoor precipitation leaching and flat plate leaching tests. The daphnia toxicity for the first outdoor precipitation leaching of IBA is about $22.8 \%$, which is classified

Table 7

Leachates from flat plate leaching tests of Marshall specimens (unit: $\mathrm{mg} / \mathrm{kg}$ )

\begin{tabular}{|c|c|c|c|c|c|}
\hline \multirow[t]{2}{*}{ Heavy metal (detection limit) } & \multirow[t]{2}{*}{ Leaching time (day) } & \multicolumn{4}{|c|}{ IBA content $(\%)$} \\
\hline & & 0 & 25 & 50 & 100 \\
\hline $\mathrm{Cd}(<0.0125)$ & $\begin{array}{r}1 \\
5 \\
10\end{array}$ & $\begin{array}{c}<0.0125 \\
0.019 \\
<0.0125\end{array}$ & $\begin{array}{c}<0.0125 \\
0.018 \\
0.019\end{array}$ & $\begin{array}{c}<0.0125 \\
0.029 \\
<0.0125\end{array}$ & $\begin{array}{c}0.014 \\
0.019 \\
<0.0125\end{array}$ \\
\hline $\mathrm{Cr}(<0.2)$ & $\begin{array}{r}1 \\
5 \\
10\end{array}$ & $\begin{array}{l}<0.2 \\
0.220\end{array}$ & $<0.2$ & $<0.2$ & $\begin{array}{l}<0.2 \\
0.218 \\
<0.2\end{array}$ \\
\hline $\mathrm{Cu}(<0.025)$ & $\begin{array}{r}1 \\
5 \\
10\end{array}$ & $<0.025$ & $\begin{array}{r}<0.025 \\
0.047 \\
<0.025\end{array}$ & $\begin{array}{r}<0.025 \\
0.045 \\
0.032\end{array}$ & $\begin{array}{r}0.048 \\
<0.025\end{array}$ \\
\hline $\mathrm{Pb}(<0.2)$ & $\begin{array}{r}1 \\
5 \\
10\end{array}$ & $<0.2$ & $<0.2$ & $<0.2$ & $\begin{array}{c}<0.2 \\
0.233 \\
<0.2\end{array}$ \\
\hline $\mathrm{Zn}(<0.0125)$ & $\begin{array}{r}1 \\
5 \\
10\end{array}$ & $<0.0125$ & $<0.0125$ & $<0.0125$ & $<0.0125$ \\
\hline
\end{tabular}


Table 8

Daphnia toxicity of outdoor leaching tests

Outdoor leaching collected after first precipitation

\begin{tabular}{llll}
\hline Material & $\begin{array}{l}\text { Treated } \\
\text { IBA }\end{array}$ & $\begin{array}{l}100 \% \text { IBA } \\
\text { asphalt mix }\end{array}$ & $\begin{array}{l}\text { Conventional } \\
\text { asphalt mix }\end{array}$ \\
\hline $\begin{array}{l}\text { LC }_{50}(\%) \\
\text { Effect category }\end{array}$ & 22.8 & 62.6 & 417.3 \\
\hline
\end{tabular}

Note: $\leqq 10 \%$ (extremely high), $>10 \%$ to $\leqq 20 \%$ (high), $>20 \%$ to $\leqq 75 \%$ (moderate), $>75 \%$ or inhibition (low), no toxic effect (no effect).

Table 9

Daphnia toxicity of flat plate leaching tests

\begin{tabular}{|c|c|c|c|c|}
\hline \multicolumn{5}{|c|}{ Flat plate leaching tests on Marshall specimens } \\
\hline \multirow{2}{*}{$\begin{array}{l}\text { Time of } \\
\text { leaching } \\
\text { (day) }\end{array}$} & \multicolumn{4}{|l|}{ IBA content $(\%)$} \\
\hline & 0 & 25 & 50 & 100 \\
\hline 1 & $\mathrm{LC}_{50}>1000 \%$ & $\mathrm{LC}_{50}>1000 \%$ & $\mathrm{LC}_{50}>800 \%$ & $\mathrm{LC}_{50}>100 \%$ \\
\hline 5 & $\mathrm{LC}_{50}>1000 \%$ & $\mathrm{LC}_{50}>1000 \%$ & $\mathrm{LC}_{50}>1000 \%$ & $\mathrm{LC}_{50}>100 \%$ \\
\hline 10 & $\mathrm{LC}_{50}>1000 \%$ & $\mathrm{LC}_{50}>135 \%$ & $\mathrm{LC}_{50}>1000 \%$ & $\mathrm{LC}_{50}>100 \%$ \\
\hline $\begin{array}{l}\text { Effect } \\
\text { category }\end{array}$ & No effect & Low & No effect & Low \\
\hline
\end{tabular}

Note: $\leqq 10 \%$ (extremely high), $>10 \%$ to $\leqq 20 \%$ (high), $>20 \%$ to $\leqq 75 \%$ (moderate), $>75 \%$ or inhibition (low), no toxic effect (no effect).

as high toxicity. Bounded with asphalt, the $\mathrm{LC}_{50}$ is increased to $62.6 \%$, which is classified as moderate toxicity.

The concentrations of heavy metal for IBA are compliant with TCLP limitations of TEPA. However, due to the experiment results of the daphnia toxicity of IBA without asphalt binder were presented high toxic effect, consequently, IBA could be identified hazardous waste in Taiwan, similar regulated on some states of USA and European countries [7,8].

Table 9 indicated the mortality rates of daphnia of the flat plate leaching tests, performed on the compacted Marshall specimen for 10 days, were very low, it can be classified as ineffective. Considering the results from the heavy metal concentration analysis with daphnia toxic analysis data, it concluded that as long as the IBA is encapsulated by asphalt binder and the asphalt mixture is well compacted, the environmental risks are small for substituting IBA as fine aggregate in asphalt mixtures. The higher risks may be caused by the inferior engineering properties and possible reduction of pavement life from the result of using IBA as aggregate substitution in pavement applications.

\section{Conclusions}

In this paper, the investigation was made on the chemical and physical properties and environmental impacts of asphalt mixtures using IBA as fine aggregate substitution. The measurements were performed including the Marshall, moisture sensitivity, and wheel tracking tests, and leaching tests for aquatic toxicity analyses. The following conclusions were drawn, according to the results obtained.

(1) The gradation of treated IBA conformed to the gradation range specified in ASTM D1073 type IV, with a nomi- nal maximum size of $9.5 \mathrm{~mm}, 70 \%$ passing $4.76 \mathrm{~mm}$, and $8 \%$ passing $0.074 \mathrm{~mm}$. The properties of the IBA improved significantly after washing process. The oven dry specific gravity increased from 1.85 to 2.28 . The absorption reduced from 15 to $6 \%$. The $\mathrm{pH}$ value changed from 12 to 10 . The percent passing $0.074 \mathrm{~mm}$ changed from 8 to $3 \%$.

(2) Using asphalt content at $4 \%$ air voids as the design asphalt content in the 50-blow Marshall mix design procedure, the design asphalt content was found to increase with the amount of IBA substitution. There was an increase of about $1 \%$ in design asphalt content for each $25 \%$ increase in IBA substitution.

(3) The aggregate blend in the IBA-asphalt mixture had higher asphalt absorption due to the higher porosity of the IBA particles. The IBA-asphalt mixtures had higher Marshall flow and lower VMA as compared with the conventional asphalt mixture. The IBA-asphalt mixtures also showed lower rutting resistance from the results of the wheel tracking tests.

(4) The results of the water sensitivity tests in accordance with AASHTO T283 method indicated that the TSR of the asphalt mixtures increased with the increase of substitution amount of IBA.

(5) The TCLP data for the IBA showed that the concentrations of the heavy metals $(\mathrm{Cd}, \mathrm{Cr}, \mathrm{Cu}$, and $\mathrm{Pb})$ were below TCLP limitations of the TEPA. Although the encapsulation of asphalt binder is not effective on reducing the $\mathrm{pH}$ value of the mixtures, the metal concentrations in leachates were considerably reduced.

(6) The daphnia toxicity, in terms of $24 \mathrm{~h} \mathrm{LC}_{50}$, for the first outdoor precipitation leaching of IBA was about $22.8 \%$, which was classified as high toxicity. When bounded with asphalt, the $\mathrm{LC}_{50}$ increased to $62.6 \%$, which was classified as moderate toxicity. The mortality rates of daphnia in the flat plate leaching tests, performed on the compacted Marshall specimen for 10 days, were very low and classified as ineffective.

(7) According to the TCLP data, when IBA was encapsulated by asphalt binder and the asphalt mixtures were well compacted, there would be very little environmental risks for substituting IBA for fine aggregate in asphalt mixtures. The higher risks are mainly caused by the inferior engineering properties, reduction of pavement life and subsequent problem with recycling of the IBA-containing materials.

A field trial on a pavement section of a secondary road with adequate design of leachate collection system was proposed for further investigation. The IBA substitution rate would be suggested as less than $25 \%$ for surface course and less than $50 \%$ for base course. The asphalt content of IBA-asphalt mixtures for surface course should be increased accordingly to the substitution rate. However, the asphalt content of IBA-asphalt mixtures for base course is not necessary to be increased simply considering the protection of surface course.

\section{Acknowledgement}

This research was part of a project (Contract Number EPA93-U1H1-02-101) supported by the Taiwan Environmental Pro- 
tection Administration. The results of toxicity test was part of another project (Project Number NSC94-2211-E-216-025) supported by the National Science Council of Taiwan. The authors also acknowledge Chung Hua University for its assistance in this research.

\section{References}

[1] The Turner-Fairbank Highway Research Center-Federal Highway Administration, U.S. Department of Transportation, User Guidelines for Waste and By-Product Materials in Pavement Construction, http://www.tfhrc.gov/, 1997, pp. 10-1-10-26.

[2] R.W. Styron, F.H. Gustin, T.L. Viness, MSW ash aggregate for use in asphalt concrete, in: H. Fred Waller (Ed.), Use of Waste Materials in Hot-Mix Asphalt, ASTM STP 1193, American Society for Testing and Materials, Philadelphia, 1993.
[3] R.J. Collins, R.H. Miller, et al., Technology for Use of Incinerator Residue as Highway Material, Federal Highway Administration, Report No. FHWA/RD-77/151, 1977.

[4] J. Haynes, W.B. Ledbetter, Incinerator Residue in Bituminous Base Construction, Federal Highway Administration, Report No. FHWA/RD-76-12, 1975.

[5] D. Gress, X. Zhang, S. Tarr, I. Pazienza, T. Eighmy, Physical and environmental properties of asphalt-amended bottom ash, in: Transportation Research Record No. 1345, TRB, National Research Council, Washington, D.C., 1992, pp. 10-18.

[6] P.O. Nelson, et al., Environmental Impact of Construction and Repair Materials on Surface and Ground Waters, Oregon State University, NCHRP Report 448, National Academy Press, Washington, D.C., 2001.

[7] USEPA, Leachability Phenomena, USEPA Science Advisory Board, Washington, D.C., 1991, EPA-SAB-EEC-92-003.

[8] USEPA, Waste Leachability: The Need for Review of Current Agency Procedures, USEPA Science Advisory Board, Washington, D.C., 1999, EPASAB-EEC-COM-99-002. 